\title{
CT assessment of nutritional status and lean body mass in gastric and esophageal cancer
}

\author{
Thais Manfrinato Miola', Elizabeth Launeir Santos da Conceição², Juliana de Oliveira Souza ${ }^{3}$, \\ Paula Nicole Vieira Barbosa ${ }^{3}$, Felipe José Fernandez Coimbra ${ }^{4}$ and Almir Galvão Vieira Bitencourt $3^{3 *}$
}

\begin{abstract}
Background: Malnutrition is common in patients with gastric and esophageal tumors, and is predominantly associated with loss of lean body mass. Adequate assessment of preoperative nutritional status is essential for prognostication and multidisciplinary treatment planning. The aim of this study was to ascertain whether anthropometric nutritional assessment correlates with computed tomography (CT) measured lean body mass in patients with gastric and/or esophageal cancer.
\end{abstract}

Methods: This was a retrospective analysis of abdominal CT images and anthropometric nutritional assessments. The anthropometric parameters of interest were weight, height, body mass index, mid-upper arm circumference, triceps skinfold thickness, mid-arm muscle circumference, and nutritional diagnosis. The lean muscle mass area was calculated from axial-view CT images of the abdomen at the level of $L 3$ and corrected by height for calculation of the lean mass index. Values below $55.4 \mathrm{~cm}^{2} / \mathrm{m}^{2}$ for males and $38.9 \mathrm{~cm}^{2} / \mathrm{m}^{2}$ for females were defined as low lean body mass.

Results: The sample included 70 patients, of whom $67.1 \%$ were men. The mean lean body mass index assessed by computed tomography was $47.8 \mathrm{~cm}^{2} / \mathrm{m}^{2}$ (range, $29.2-78.6 \mathrm{~cm}^{2} / \mathrm{m}^{2}$ ), with $54.3 \%$ of patients being classified as having low lean body mass. When classified by mid-arm muscle circumference, $74.2 \%$ of patients classified as undernourished had low lean body mass on CT, compared to $40.0 \%$ of patients classified as well-nourished (sensitivity 62.2\%, specificity $72.4 \%$, accuracy $66.7 \%$ ).

Conclusions: A substantial portion of patients with gastric and/or esophageal cancer exhibited low lean body mass on computed tomography. Anthropometric evaluation has limited capacity to identify these patients. Among the tested anthropometric parameter, mid-arm muscle circumference showed the best agreement with CT-measured lean body mass.

Keywords: Oncology, Nutritional assessment, Computed tomography

\section{Background}

Cancer has become a global public health problem, and is currently the second leading cause of death by illness worldwide [1]. It is estimated that, between 2000 and 2020 , overall cancer rates will increase by $50 \%$, resulting in an incidence of 10 to 15 million cases [2].

\footnotetext{
* Correspondence: almirgvb@yahoo.com.br

${ }^{3}$ Imaging Department, A.C. Camargo Cancer Center, R. Prof. Antonio

Prudente, 211, São Paulo, SP 09015-010, Brazil

Full list of author information is available at the end of the article
}

In addition to the major metabolic changes triggered by the disease itself, the adverse effects of current treatment modalities can also affect the nutritional status of the patient. Surgery, radiation therapy, chemotherapy, or any combination thereof can cause a series of side effects that contribute to reduced food intake and subsequent malnutrition, including pain, constipation, nausea, vomiting, mucositis, and anorexia [3].

In patients with cancer, nutritional status should be assessed throughout the course of treatment, starting at the time of diagnosis, with the objective of ascertaining

(c) The Author(s). 2018 Open Access This article is distributed under the terms of the Creative Commons Attribution 4.0 International License (http://creativecommons.org/licenses/by/4.0/), which permits unrestricted use, distribution, and 
nutritional status and preventing deterioration of the patient's general physical condition. Nutritional assessment also identifies patients who are undernourished, which contributes to evaluation of surgical risk [4].

According to the Brazilian National Cancer Institute (INCA, 2013), approximately 40 to $80 \%$ of cancer patients are malnourished. Several factors can be involved, including low food intake, metabolic changes, physiological changes, symptoms of the disease itself, and adverse effects of treatment [4].

According to Von Meyenfeldt [5], a substantial prevalence of malnutrition (around 60-85\%) is found among patients with gastric and esophageal cancer. Weight loss is reported as a common consequence in patients undergoing gastrectomy and/or esophagectomy [6]. Cancer-associated malnutrition has negative consequences, such as increased postoperative complication rates, increased risk of infection, slower wound healing, decreased treatment tolerance, decreased quality of life, and increased mortality [7].

Several methods that can be used to evaluate body composition, from conventional anthropometry using the body mass index (BMI) and skinfold thicknesses to bioimpedance and imaging methods, such as dual-energy X-ray absorptiometry (DEXA), computed tomography (CT), magnetic resonance imaging (MRI), and ultrasound, but each method has its limitations [8].

The aim of this study was to assess whether CT-evaluated lean body mass correlates with anthropometric nutritional assessment in patients undergoing surgical treatment for gastric and/or esophageal cancer.

\section{Methods}

This retrospective study was performed through a review of abdominal CT images and anthropometric nutritional assessment data collected from the charts of patients who underwent gastrectomy and esophagectomy at a cancer center in 2015. Patients whose medical records lacked anthropometric nutritional assessment data or for whom no abdominal CT scans were available were excluded from the study. This project was approved by the institutional Research Ethics Committee (decision no. 2309/16) before the start of data collection.

We retrospectively analyzed CT images obtained as part of routine preoperative evaluation, according to the protocol of the Department of Abdominal Surgery of the A.C.Camargo Cancer Center (São Paulo, Brazil). We only considered $\mathrm{CT}$ examinations performed until 4 months prior to surgery and the mean time between $\mathrm{CT}$ and surgery was 41 days. Body composition was evaluated in the OsiriX $\mathrm{X}^{\circ}$ software environment, using previously validated parameters widely used in the literature [9-11]. Nonenhanced axial CT images of the abdomen obtained at the level of the lower portion of L3 were examined. All images were reviewed by the same radiologist, who has 10 years experience in cancer imaging. To measure the surface area of lean body mass (skeletal muscles, including the psoas, paravertebral, and abdominal wall muscles), a semi-automatic method with manual correction was used as necessary (Fig. 1). A CT density of -29 to +150 Hounsfield units (HUs) was used to identify the skeletal muscles. The lean body mass area was corrected by height (lean mass in $\mathrm{cm}^{2} /$ height in $\mathrm{m}^{2}$ ) for calculation of the lean mass index. Lean body mass was considered low when the index at the L3 level was less than $55.4 \mathrm{~cm}^{2} / \mathrm{m}^{2}$ for males and $38.9 \mathrm{~cm}^{2} / \mathrm{m}^{2}$ for females [12].

The anthropometric parameters of interest were weight, height, BMI, mid-upper arm circumference (MUAC), triceps skinfold thickness (TSF), and mid-arm muscle circumference (MAMC). MUAC and TSF measurements were obtained using a tape measure and Lange adipometer, respectively, and used to calculate the MAMC. These measurements were classified as proposed by Frisancho [13] for patients up to 60 years of age, and as proposed by Kuczmarski et al. [14] for older patients. Weight and height measurements were used to calculate the BMI, using the formula $B M I=W / h^{2}$ [15]. The World Health Organization (WHO) 1995 reference values $^{2}$ were used for patients up to 60 years of age, while the Pan American Health Organization (PAHO) reference values [15] were used for older patients.

The information collected from the CT images and the electronic medical record was exported to a Microsoft Excel spreadsheet. Data were processed in the Statistical Package for the Social Sciences (SPSS) Version 2.0 software environment. For descriptive analysis, conventional measures of central tendency (mean, median, mode) and dispersion (range, variance, standard deviation, and coefficient of variation) were used, and absolute and relative frequencies were calculated. To test for correlation between variables, the chi-square and Fisher's exact test were used for frequencies of the categorical variables; Student's $t$-test for normally distributed continuous variables; and the Mann-Whitney $U$ for continuous variables without a normal distribution. The level of significance was set at $5 \%$.

\section{Results}

The sample comprised 70 patients: 18 with esophageal cancer and 52 with gastric cancer. Overall, 54 (77.1\%) had received neoadjuvant chemotherapy. The mean age was $59.9(33-82)$ years; $47(67.1 \%)$ were men and 23 (32.9\%) were women. The most prevalent comorbidities were hypertension $(30 \%)$, smoking $(30 \%)$, diabetes mellitus (15.7\%), and dyslipidemia (4.3\%).

The patients' current mean (SD) weight was 70.01 (15.27) kg, height was $1.66(0.10) \mathrm{m}$, and BMI was 25.34 (4.72) $\mathrm{kg} / \mathrm{m}^{2}$. The mean MUAC was 29.0 (4.1) cm, with a mean adequacy of $91.9(12.9) \%$. The mean TSF was 


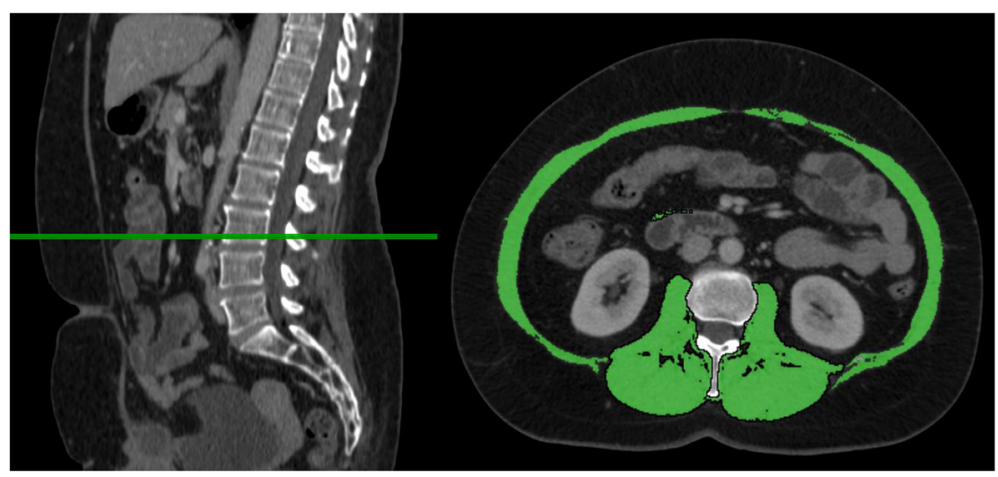

Fig. 1 Measurement of lean body mass area in an axial CT slice obtained at the L3 level

16.5 (8.6) $\mathrm{mm}$, with a mean adequacy of $98.8(45.9) \%$. The mean MAMC was 23.9 (3.1) $\mathrm{cm}$, with a mean adequacy of 90.1 (16.3)\%.

According to BMI, 8 (11.4\%) patients were classified as underweight, 39 (55.7\%) as having normal weight, 14 (20.0\%) as overweight, and 9 (12.9\%) as obese. According to MUAC, 33 (47.8\%) patients were classified as malnourished, $31(44.9 \%)$ as well-nourished, 2 (2.9\%) as overweight, and $3(4.3 \%)$ as obese. According to TSF, 31 (44.3\%) patients were classified as malnourished, 13 (18.6\%) as well-nourished, 5 (7.1\%) as overweight, and 17 (24.3\%) as obese. According to MAMC, 31 (47.0\%) patients were classified as malnourished and 35 (53.0\%) as well-nourished. The final nutritional diagnosis was malnutrition in 26 (37.1\%), adequate nutrition in 25 (35.7\%), overweight in $11(15.7 \%)$, and obesity in 8 (11.4\%).

The mean lean body mass area assessed by CT at the L3 level was $133.6 \mathrm{~cm}^{2}$ (range, $80.4-238.1 \mathrm{~cm}^{2}$; SD, $31.8 \mathrm{~cm}^{2}$ ). The mean lean mass index was $47.8 \mathrm{~cm}^{2} / \mathrm{m}^{2}$ (range, 29.2$78.6 \mathrm{~cm}^{2} / \mathrm{m}^{2}$; SD, $\left.8.6 \mathrm{~cm}^{3} / \mathrm{m}^{2}\right)$. Of the 70 patients evaluated, 38 (54.3\%) were classified as having low lean body mass and $32(45.7 \%)$ as having normal lean body mass. There were weak, positive correlations between lean mass index and BMI $(r=0.418, p<0.01)$, MUAC $(r=0.325, p<$ $0.01)$, and MAMC $(r=0.409, p<0.01)$. There was no correlation between lean mass index and TSF.

Of the patients classified as underweight by BMI, $87.5 \%$ had low lean mass on CT; however, $50 \%$ of patients classified as well-nourished (normal weight, overweight, or obese) also had low lean mass on CT (sensitivity 18.4\%, specificity $96.7 \%$, accuracy $54.3 \%$ ). When classified by MUAC, $69.7 \%$ of patients classified as undernourished and $38.9 \%$ of patients classified as well-nourished had low lean body mass on CT (sensitivity $62.2 \%$, specificity $68.8 \%$, accuracy $65.2 \%$ ). According to TSF, $61.3 \%$ of patients classified as undernourished had low lean body mass on CT, compared to $51.4 \%$ of patients classified as well-nourished (sensitivity $51.4 \%$, specificity $58.6 \%$, accuracy $54.5 \%$ ). When classified by MAMC, $74.2 \%$ of patients classified as undernourished and $40.0 \%$ of those classified as well-nourished had, low lean body mass on CT (sensitivity 62.2\%, specificity $72.4 \%$, accuracy $66.7 \%$ ). On final nutritional diagnosis, $65.4 \%$ of patients classified as undernourished and $47.7 \%$ of those classified as well-nourished had low lean body mass on CT (sensitivity $44.7 \%$, specificity $71.9 \%$, accuracy $57.1 \%$ ). These data are presented in detail in Table 1.

\section{Discussion}

This study found that more than half of patients with gastric and/or esophageal cancer had low lean body mass on preoperative CT. There was a weak correlation between CT-evaluated lean body mass index and the anthropometric parameters assessed (BMI, MUAC, and MAMC). Among these, MAMC yielded the best sensitivity, specificity, and accuracy for diagnosis of low body lean mass.

It is essential that the nutritional status of cancer patients be evaluated since the time of diagnosis, as undernourished patients respond poorly to therapeutic intervention and experience a higher incidence of postoperative complications, longer hospital stays, greater immune impairment, worse quality of life, and higher morbidity and mortality when compared to well-nourished cancer patients [16]. Nutritional care of these patients should be individualized throughout the treatment process, from nutritional screening through calculation of energy needs and nutritional therapy all the way to outpatient follow-up, with the aim of preventing or reversing a decline in the patient's nutritional status [5].

Anthropometry is a simple, low-cost, noninvasive method, but studies claim that databases are limited and correction factors are insufficient [17]. BMI is a well-known anthropometric parameter and is widely used in nutritional practice, but most studies state that it is highly imprecise, as it does not separate fat body mass from lean body mass, thus generalizing classification of the patient's nutritional status [5]. In addition, the proposed cutoff points for BMI commonly 
Table 1 Correlation between lean body mass evaluated by CT with nutritional classification based in anthropometric data

\begin{tabular}{|c|c|c|c|}
\hline \multirow{2}{*}{$\begin{array}{l}\text { Nutritional } \\
\text { classification }\end{array}$} & \multicolumn{2}{|c|}{ Lean body mass evaluated by $\mathrm{CT}$} & \multirow[t]{2}{*}{ Total } \\
\hline & Low & Normal & \\
\hline \multicolumn{4}{|l|}{ Body Mass Index } \\
\hline Malnutrition & $7(87.5 \%)$ & $1(12.5 \%)$ & $8(100 \%)$ \\
\hline Normal & $25(64.1 \%)$ & $14(35.9 \%)$ & $39(100 \%)$ \\
\hline Overweight & $5(35.7 \%)$ & $9(64.3 \%)$ & $14(100 \%)$ \\
\hline Obesity & $1(11.1 \%)$ & $8(88.9 \%)$ & $9(100 \%)$ \\
\hline \multicolumn{4}{|c|}{ Mid-Upper Arm Circumference } \\
\hline Malnutrition & $23(69.7 \%)$ & $10(30.3 \%)$ & $33(100 \%)$ \\
\hline Normal & $13(41.9 \%)$ & $18(58.1 \%)$ & $31(100 \%)$ \\
\hline Overweight & $0(0.0 \%)$ & $2(100 \%)$ & $2(100 \%)$ \\
\hline Obesity & $1(33.3 \%)$ & $2(66.7 \%)$ & $3(100 \%)$ \\
\hline \multicolumn{4}{|c|}{ Triceps Skinfold Thickness } \\
\hline Malnutrition & $19(61.3 \%)$ & $12(38.7 \%)$ & $31(100 \%)$ \\
\hline Normal & $8(61.5 \%)$ & $5(38.5 \%)$ & $13(100 \%)$ \\
\hline Overweight & $1(20.0 \%)$ & $4(80.0 \%)$ & $5(100 \%)$ \\
\hline Obesity & $9(52.9 \%)$ & $8(47.1 \%)$ & $17(100 \%)$ \\
\hline \multicolumn{4}{|c|}{ Mid-Arm Muscle Circumference } \\
\hline Malnutrition & $23(74.2 \%)$ & $8(25.8 \%)$ & $31(100 \%)$ \\
\hline Normal & $14(40.0 \%)$ & $21(60.0 \%)$ & $35(100 \%)$ \\
\hline \multicolumn{4}{|c|}{ Final Nutritional Diagnosis } \\
\hline Malnutrition & $17(65.4 \%)$ & $9(34.6 \%)$ & $26(100 \%)$ \\
\hline Normal & $17(68.0 \%)$ & $8(32.0 \%)$ & 25 (100\%) \\
\hline Overweight & $3(27.3 \%)$ & $8(72.7 \%)$ & $11(100 \%)$ \\
\hline Obesity & $1(12.5 \%)$ & $7(87.5 \%)$ & $8(100 \%)$ \\
\hline
\end{tabular}

used in nutritional status assessment are applied across a very broad age range, and disregard gender and ethnicity [18]. According to Deurenberg-Yap et al., the relationship between BMI and body fat is significantly different across ethnic groups [19].

In the present study, BMI did not correlate well with CT evaluation of lean body mass. Fruchtenicht et al. have noted that, when applied alone, anthropometric parameters such as BMI and weight loss do not reflect an individual's actual nutritional status [15]. In another study, Duarte et al. found that BMI does not express individual body composition accurately, as it is incapable even of predicting body fat percentage and its distribution, much less quantifying lean mass [20]. Acuña et al. found a weak correlation between BMI and the Index Suggestive of Malnutrition (ISM), and concluded that BMI is not a good parameter for evaluating hospitalized adults, as a thin person may be well-nourished while an obese person may be malnourished [21]. These findings were confirmed by Thoresen et al. [22], who observed that, in a sample of 47 patients classified as having normal weight by BMI, 15 had low lean body mass and should be classified as sarcopenic.
Among the various imaging methods used to evaluate body composition, DEXA and CT stand out. DEXA is currently considered the gold standard for body composition assessment. This "scanning" technique measures the different attenuations of dual X-ray beams that pass through the patient's body, allowing segmented study of the main anatomical regions (head, trunk, and limbs) for evaluation of different body composition parameters, such as bone mass, lean mass, and fat mass. This technique is considered safe and noninvasive [18, 23]. Its major advantage is that it can be used in any age group, because radiation exposure is low. However, it is contraindicated in pregnant women. The main disadvantage of the method is that very tall or obese individuals may not fit in the scanner [24].

CT allows detailed, precise measurement of lean body mass, as well as visceral and subcutaneous fat in the abdominal region. Its advantage is that most cancer patients will undergo CT scanning anyway for disease staging and surgical planning; thus, using these scans to assess body composition avoids further exposure to ionizing radiation [24, 25]. Recently, several authors have demonstrated the association between CT-assessed low body mass and postoperative complications in patients with gastric and/or esophageal cancer [26, 27].

The present study has some limitations. Because of the retrospective design, some patients were excluded because they did not have nutritional assessment data or CT images available for analysis. Cancer staging was not included in this study due to the lack of standardized data in medical records. Furthermore, possible functional changes related to low body lean mass were not evaluated, which precluded a diagnosis of sarcopenia in this population.

\section{Conclusion}

Cancer patients should undergo evaluation of lean body mass so that the most appropriate nutritional diagnosis can be established. A substantial portion of the patients with gastric and/or esophageal cancer in our sample exhibited low lean body mass on CT, and anthropometric evaluation had limited capacity to identify these patients. The anthropometric parameter that demonstrated the best agreement with CT-measured lean body mass was the mid-arm muscle circumference, which highlights the importance of including this measurement in the nutritional evaluation of cancer patients.

\section{Abbreviations}

BMI: Body mass index; CT: Computed tomography; DEXA: Dual-energy X-ray Absorptiometry; Hus: Hounsfield units; INCA: Brazilian National Cancer Institute; ISM: Index suggestive of malnutrition; MAMC: Mid-arm muscle circumference; MRI: Magnetic resonance imaging; MUAC: Mid-upper arm circumference; PAHO: Pan American Health Organization; SPSS: Statistical Package for the Social Sciences; TSF: Triceps skinfold thickness; WHO: World Health Organization 


\section{Funding}

No funding received.

\section{Availability of data and materials}

The datasets analysed during the current study available from the corresponding author on reasonable request.

\section{Authors' contributions}

TMM e AGVB designed the research. ELSC e JOS performed the research. All authors analyzed the data, wrote/revised the paper. All authors read and approved the final manuscript.

\section{Ethics approval and consent to participate}

This project received approval from the institution's Research Ethics Committee (no. 2309/16).

\section{Consent for publication}

Not applicable.

\section{Competing interests}

The authors declare that they have no competing interests. All procedures performed in this study were in accordance with the ethical standards of the institutional research committee and with the 1964 Helsinki declaration and its later amendments.

\section{Publisher's Note}

Springer Nature remains neutral with regard to jurisdictional claims in published maps and institutional affiliations.

\section{Author details}

${ }^{1}$ Nutrition Department, A.C. Camargo Cancer Center, São Paulo, SP, Brazil. ${ }^{2}$ Universidade Nove de Julho, São Paulo, SP, Brazil. ${ }^{3}$ Imaging Department, A.C. Camargo Cancer Center, R. Prof. Antonio Prudente, 211, São Paulo, SP 09015-010, Brazil. ${ }^{4}$ Department of Abdominal Surgery, A.C. Camargo Cancer Center, São Paulo, SP, Brazil.

Received: 8 February 2018 Accepted: 26 July 2018

Published online: 14 August 2018

\section{References}

1. Ferlay J, Soerjomataram I, Ervik M, Dikshit R, Eser S, Mathers C, et al. Cancer incidence and mortality worldwide: sources, methods and major patterns in GLOBOCAN 2012. Int J Cancer. 2015;136(5):E359-86.

2. $\mathrm{WHO}$, World Health Organization. Physical status: the use and interpretation of anthropometry. Geneva: Report of a WHO expert committee; 1995.

3. Toscano BAF, Coelho MS, Abreu HB, Logrado MHG, Fortes RC. Câncer: implicações nutricionais. Comunic Cienc Saúde. 2008:19(2):171-80.

4. Instituto Nacional de Câncer José Alencar Gomes da Silva. Consenso nacional de nutrição oncológica. 2nd ed. Rio de Janeiro: INCA; 2013.

5. Meyenfeldt V. Cancer-associated malnutrition: an introduction. Eur J Oncol Nurs. 2005;9(Suppl 2):S35-8.

6. Kamiji MM, Oliveira RB. Estado nutricional e avaliação dietética de pacientes gastrectomizados. Arq Gastroenterol. 2003;40(2):85-91.

7. Caro MMM, Laviano A, Pichard C. Nutritional intervention and quality of life in adult oncology patients. Clin Nutr. 2007;26:289-301.

8. Martins KA, Monego ET, Paulinelli RR, Freitas-Junior R. Comparação de métodos de avaliação da gordura corporal total e sua distribuição. Rev bras Epidemiol. 2011:14(4):677-87.

9. Doyle SL, Bennett AM, Donohoe CL, Mongan AM, Howard JM, Lithander FE, et al. Establishing computed tomography-defined visceral fat area thresholds for use in obesity related cancer research. Nutr Res. 2013;33:171-9.

10. Mitsiopoulos N, Baumgartner RN, Heyms-field SB, Lyons W, Gallagher D, Ross R. Cadaver validation of skeletal muscle measurement by magnetic resonance imaging and computerized tomography. J Appl Physiol. 1998;85:115-22.

11. Mourtzakis M, Prado CM, Lieffers JR, Reiman T, McCargar $L$, Baracos VE. A practical and precise approach to quantification of body composition in cancer patients using computed tomography images acquired during routine care. Appl Physiol Nutr Metab. 2008;33:997-1006.
12. Prado CM, Lieffers JR, McCargar $L$, Reiman $T$, Sawyer MB, Martin $L$, et al. Prevalence and clinical implications of sarcopenic obesity in patients with solid tumours of the respiratory and gastrointestinal tracts: a populationbased study. Lancet Oncol. 2008;9:629-35.

13. Frisancho AR. New norms of upper limb fat and muscle areas for assessment of nutritional status. Am J Clin Nutr. 1981;24(11):2540-5.

14. Kuczmarski MF, Kuczmarski RJ, Najjar M. Descriptive anthropometric reference data for older Americans. J Am Diet Assoc. 2000;100:59-66.

15. Fruchtenicht AVG, Poziomyck AK, Kabke GB, Loss SH, Antoniazzi IL, Steemburgo T, et al. Avaliação do risco nutricional em pacientes oncológicos graves: revisão sistemática. Rev Bras Ter Intensiva. 2015;27(3):274-83.

16. Machry RV, Susin CF, Barros RC, Lago LD. Desnutrição em pacientes com câncer avançado: uma revisão com abordagem para o clínico. Revista da AMRIGS. 2011;55(3):296-301.

17. Poziomych AK, Fruchtenicht AVG, Kabke GA, Volkweis BS, Antoniazzi JL, Moreira LF. Reliability of nutritional assessment in patients with gastrointestinal tumors. Rev Col Bras Cir. 2016;43(3):189-97.

18. Santanna MSL, Priore SE, Franceschini SCC. Métodos de avaliação da composição corporal em crianças. Rev Paul Pediatr. 2009;27(3):315-21.

19. Deurenberg-Yap M, Schmidt G, Staveren WA, Deurenberg P. The paradox of low body mass index and high body fat percentage among Chinese, Malays and Indians in Singapore. Int J Obes. 2000;24(8):1011-7.

20. Duarte CRF, Botelho LP, Machado MS, Lopes ACS, Lopes Filho JD, Jansen AK. Correlação entre índice de massa corporal, distribuição de gordura e composição corporal em funcionários de um hospital universitário da região metropolitana de Belo Horizonte-MG. REME Rev Min Enferm. 2009;13(1):131-8.

21. Acuña K, Portela M, Costa-Matos A, Bora L, Teles MR, Waitzberg DL, et al. Nutritional Assessment of Adult Patients Admitted to a Hospital of the Amazon Region. Nutr Hosp. 2003;18(3):138-46.

22. Thoresen L, Frykholm G, Lydersen S, Ulveland H, Baracos V, Prado CM, et al. Nutritional status, cachexia and survival in patients with advanced colorectal carcinoma. Different assessment criteria for nutritional status provide unequal results. Clin Nutr. 2013:32:65-72.

23. Silva TAA, Frisoli Junior A, Pinheiro MM, Szejnfeld VL. Sarcopenia associada ao envelhecimento: aspectos etiológicos e opções terapêuticas. Rev Bras Reumatol. 2006;46(6):391-7.

24. Souza RGM, Gomes AC, Prado CMM, Mota JF. Métodos de análise da composição corporal em adultos obesos. Rev Nutr. 2014;27(5):569-83.

25. Eickemberg M, Oliveira CC, Roriz AKC, Fontes GAV, Mello AL, Sampaio LR. Bioimpedância elétrica e gordura visceral: uma comparação com a tomografia computadorizada em adultos e idosos. Arq Bras Endocrinol Metab. 2013:57(1):27-32.

26. Fukuda Y, Yamamoto K, Hirao M, Nishikawa K, Nagatsuma Y, Nakayama T, et al. Sarcopenia is associated with severe postoperative complications in elderly gastric cancer patients undergoing gastrectomy. Gastric Cancer. 2016:19(3):986-93.

27. Wang SL, Zhuang CL, Huang DD, Pang WY, Lou N, Chen FF, et al. Sarcopenia adversely impacts postoperative clinical outcomes following gastrectomy in patients with gastric Cancer: a prospective study. Ann Surg Oncol. 2016:23(2):556-64.

Ready to submit your research? Choose BMC and benefit from

- fast, convenient online submission

- thorough peer review by experienced researchers in your field

- rapid publication on acceptance

- support for research data, including large and complex data types

- gold Open Access which fosters wider collaboration and increased citations

- maximum visibility for your research: over $100 \mathrm{M}$ website views per year

At BMC, research is always in progress.

Learn more biomedcentral.com/submission 